TEMAS DE ACTUALIDAD Rev Chil Salud Pública 2013; Vol 17 (1): 11-21

\section{Propiedad intelectual farmacéutica, salud pública y libre comercio: iEl actual modelo maximiza el bienestar para los países en vías de desarrollo?}

\section{RESUMEN}

El presente trabajo busca describir ciertos dilemas a los que se ven enfrentados los paises en vías de desarrollo para elegir su modelo regulatorio de propiedad intelectual farmacéutica, que tienda al nivel óptimo en términos de bienestar, es decir, donde exista un debido balance entre incentivos a la I\&D farmacéutico y el acceso a medicamentos.

Para ello se describe el modelo teórico de funcionamiento de un sistema de propiedad intelectual farmacéutica. Se explica, además, cómo los tratados de libre comercio disminuyen la libertad de elección de un sistema adecuado para paises en vias de desarrollo.

Finalmente, se ejemplifica las pérdidas de bienestar que un modelo de propiedad intelectual farmacéutica desbalanceado puede generar, mediante el ejemplo del linkage y la que denominaremos competencia polimórfica.

Palabras claves: Patentes farmacéuticas, acceso a medicamentos, tratados de libre comercio, polimorfismo y linkage.

\section{Pharmaceutical Intellectual Property, Public Health, and Free Trade: Does the current model maximize wellbeing FOR DEVELOPING COUNTRIES?}

\begin{abstract}
When choosing a regulatory model for pharmaceutical intellectual property, developing countries must seek a balance between I\&D incentives and access to medications.

This article describes the operating theoretical framework for a pharmaceutical intellectual property system. Mechanisms through which free trade agreements decrease freedom of choice in order to choose a suitable system for developing countries are also explained.

Finally, several examples will be given of the negative impact on wellbeing that an unequal pharmaceutical intellectual property system can produce, specifically the examples of linkage and what we will call polymorphic competition.

Key words: Pharmaceutical patents, access to medications, free trade agreements, polymorphism and linkage.
\end{abstract}

\section{INTRODUCCIÓN}

Existen varios factores que contribuyen al crecimiento económico y a la creación de bienestar en general, dentro de los cuales se encuentra la innovación ${ }^{1,2}$. Por otro lado, también está vastamente documentado cómo la propiedad intelectual ("PI") ${ }^{3}, \mathrm{y}$ 
especialmente las patentes de invención, están positivamente correlacionadas con los niveles de innovación, en tanto mecanismos de retribución del esfuerzo financiero realizado en ella.

Ahora, el resultado positivo entre los sistemas de PI y los grados de innovación ("I\&D"), en términos de creación de bienestar, puede variar si se analiza el impacto de éstos en relación a necesidades vinculadas con la salud pública, tales como el acceso a medicamentos: $\mathrm{El}$ acceso a medicamentos a precios asequibles también juega un rol importante en términos de niveles de salud pública, los que también están directamente correlacionados con el crecimiento económico y mayores niveles de bienestar ${ }^{4-6}$.

En ese sentido, existen estudios que confirman que los niveles de salud pública están positivamente vinculados con la productividad en un nivel micro ${ }^{7}$, y con el crecimiento económico a un nivel macro ${ }^{8,9}$.

Bajo ese contexto, un sistema de PI farmacéutica muy "fuerte" (que impida la competencia de productos genéricos en forma relevante), puede generar, por un lado, mayor innovación farmacéutica $^{2}$ (síntesis de nuevas entidades químicas), pero, por el otro, puede afectar el nivel de salud pública de un determinado país, por lo que el efecto combinado de estos factores, puede tender a ser subóptimo en términos de bienestar. Por el contrario, un sistema de PI farmacéuticas muy "débil", puede tener un efecto negativo en términos de innovación farmacéutica, afectando tanto los niveles de salud pública como, en definitiva, la creación de bienestar (representado en la Figura 1).

En este contexto, el presente trabajo busca describir ciertos dilemas a los que se ven enfrentados los países en vías de desarrollo para elegir su modelo de PI farmacéutica que tienda al nivel óptimo antes señalado, es decir, donde exista un debido balance entre incentivos a la I\&D farmacéutico y el acceso a medicamentos.

Para ello, en primer lugar, se va a describir el modelo teórico de funcionamiento de un sistema de PI farmacéutico. Posteriormente, se van a indicar las dificultades que tiene un país en vías de desarrollo para poder elegir el modelo que logre optimizar el efecto combinado. Finalmente, se va a ejemplificar las pérdidas de bienestar que un modelo de PI farmacéutica desbalanceado puede generar, mediante el ejemplo del Linkage y la que denominaremos competencia polimórfica.

\section{EL MODELO TEÓRICO Y ALGUNAS INTERROGANTES}

Es prácticamente un lugar común sostener que la $I \& D$ farmacéutico es costoso y con tasas de falla relevantes ${ }^{10,11}$, no obstante el constante debate que sigue existiendo respecto a su verdadera magnitud $^{12}$.

Asumiendo la existencia de dichos altos costos, el modelo teórico de PI farmacéutica, debiese buscar que

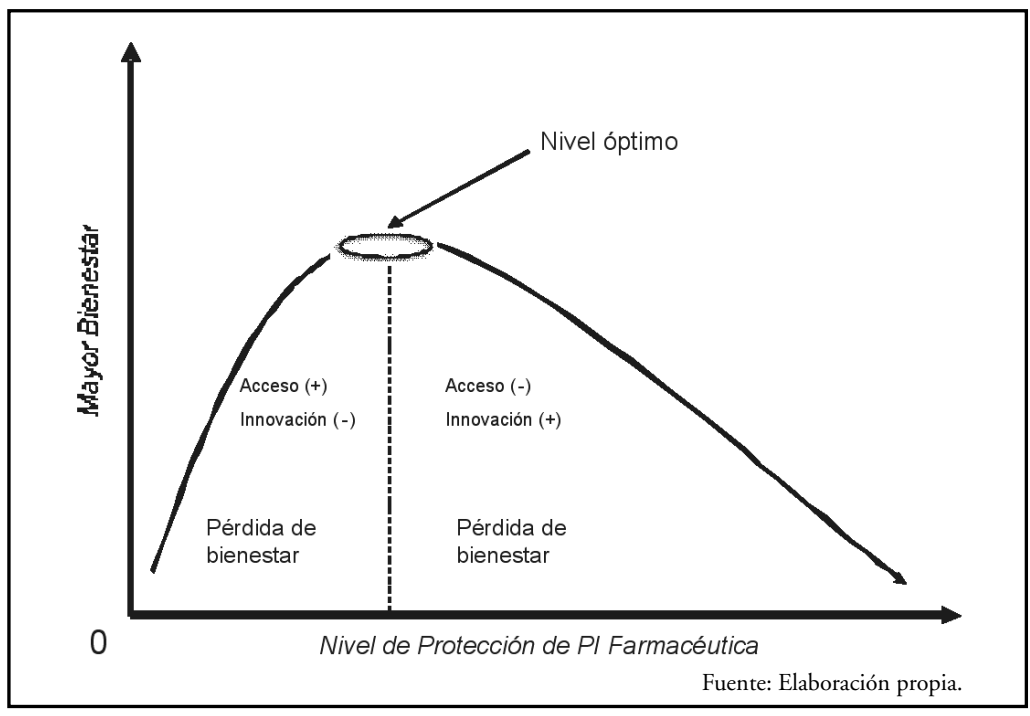

Figura 1. Representación del Efecto Combinado 


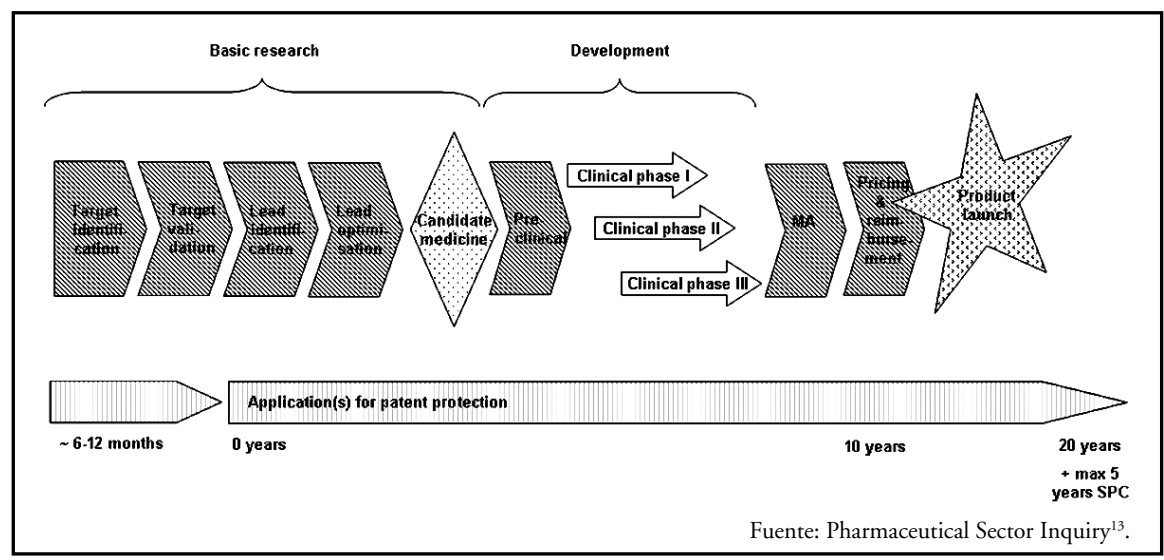

Figura 2. Proceso de I\&D farmacéutico hasta el lanzamiento al mercado.

el valor presente de los flujos futuros provenientes del período de tiempo en que el producto innovador se encuentra en una posición monopólica, con precios supra-competitivos $\left(Q_{i}^{*} P_{i}\right.$ : rentas monopólicas), más aquellos en que imperen precios con presión competitiva de los genéricos y erosión de precios $\left(Q_{\sigma}^{*} P\right)$, menos los costos en I\&D $(X)$, sea superior a 0 (VAN $<0$; representado en la Figura 3).

Por ello, unas las preguntas más relevante para la definición de un modelo de PI farmacéutica es cuánto tiempo debe durar el período en que el producto innovador debe estar protegido por PI farmacéutica $\left(Q_{i}^{*} P_{i}\right)$ y qué debiese estar protegido (materias patentables).
Como hemos planteado previamente ${ }^{14}$, el cuánto y el qué son sólo las preguntas iniciales (estándar de PI aplicable) de un modelo de PI farmacéutica, ya que el nivel efectivo de PI farmacéutico en un país dado será el resultado de la interacción entre aquellos que buscan obtener la protección de PI y aquellos que se opondrán a ésta (mediante presentación de oposiciones o nulidades de la PI solicitada o concedida).

Estas interrogantes son relevantes, ya que el diseño de un modelo de PI farmacéutica debiese adaptarse a la realidad de cada país de manera de optimizar el efecto combinado: En términos relativos, los países generadores de I\&D farmacéutico (habitualmente

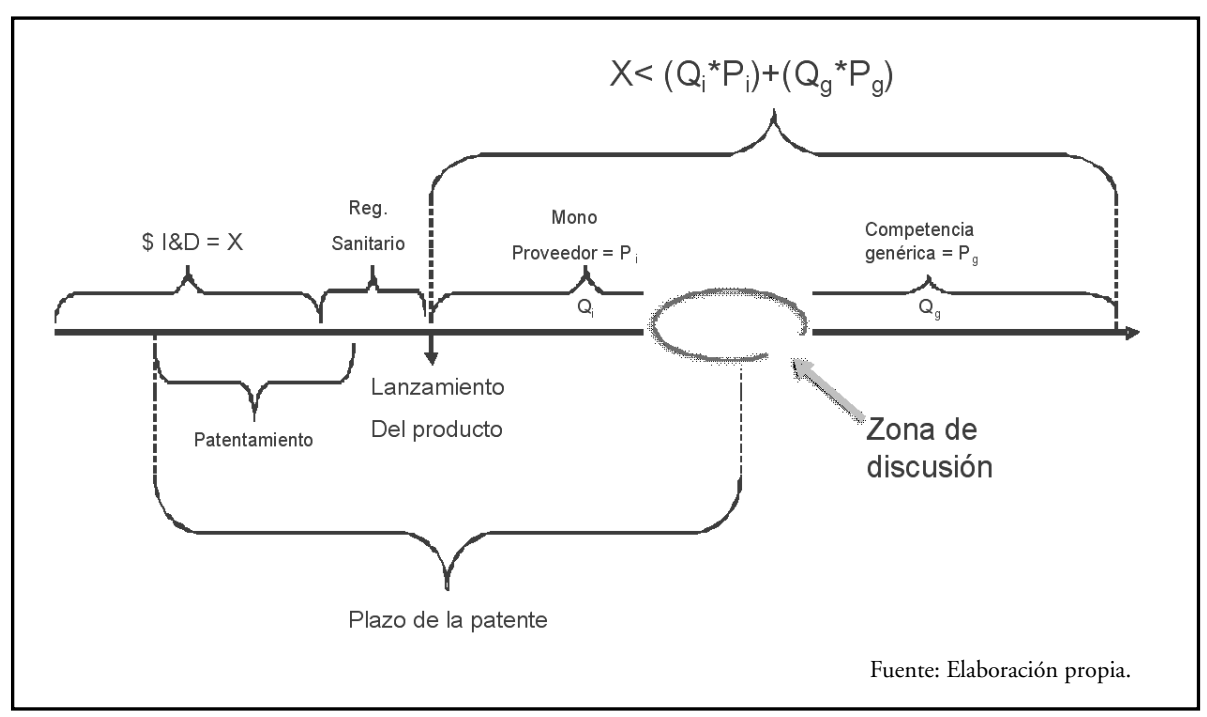

Figura 3. Línea de tiempo. 
son países desarrollados) se benefician más de un sistema de PI más fuerte -dado que pueden apropiarse de sus externalidades positivas- que países que no son generadores de I\&D (habitualmente subdesarrollados o en vías de desarrollo) $)^{15}$.

En buenas cuentas, la adopción modelos de PI fuertes en países no generadores de I\&D farmacéutica, ceteris paribus tenderá a producir pérdidas de bienestar por su impacto en la salud pública (acceso a medicamentos).

\section{¿ELIGEN LOS PAÍSES EN VÍAS DE DESARROLLO SU MODELO DE PI FARMACÉUTICA?: LA INFLUENCIA DEL LIBRE COMERCIO}

La respuesta es que sólo lo eligen dentro de márgenes estrechos. ¿Por qué ocurre esto?

En primer lugar, es relevante entender que los mayores interesados en establecer estándares de PI farmacéuticos, son precisamente países desarrollados, generadores de I\&D. En efecto, como se aprecia en las Figuras 4 y 5 , son países como EE.UU. y los centro europeos, además de Japón, los que concentran en mayor medida la $I \& D$ farmacéutica.
Coherente resulta, desde su perspectiva, que dichos países generadores de I\&D farmacéutico busquen proteger sus productos innovadores no sólo en el país de origen, sino que también en los países donde estos son exportados.

Pues bien, ¿cómo se realiza esto? Fundamentalmente, por medio de tratados multi ${ }^{16} \mathrm{y}$ bilaterales ${ }^{17,18}$ de libre comercio (TLCs) donde se impulsan estándares de PI farmacéuticos fuertes. La pregunta que sigue, entonces, es ¿por qué un país en vías de desarrollo estaría dispuesto a comprometerse a implementar dentro de su ordenamiento jurídico interno estándares de PI farmacéutica fuertes, es decir, no adecuados a su realidad?

Como explica Roffe, los estándares de PI farmacéuticos fuertes (denominados convencionalmente Trips-Plus), son acordadas habitualmente entre países desarrollados con aquellos en vías de desarrollo, como contraprestación por "acceso a mercado", que los primeros les darán a los últi$\operatorname{mos}^{19}$. En buenas cuentas, a los primeros les interesa proteger su innovación farmacéutica y a los segundos, poder acceder a dichos mercados con sus productos (habitualmente de bajo valor agregado): Ese es el trade-off de dichas negociaciones, en términos gruesos.

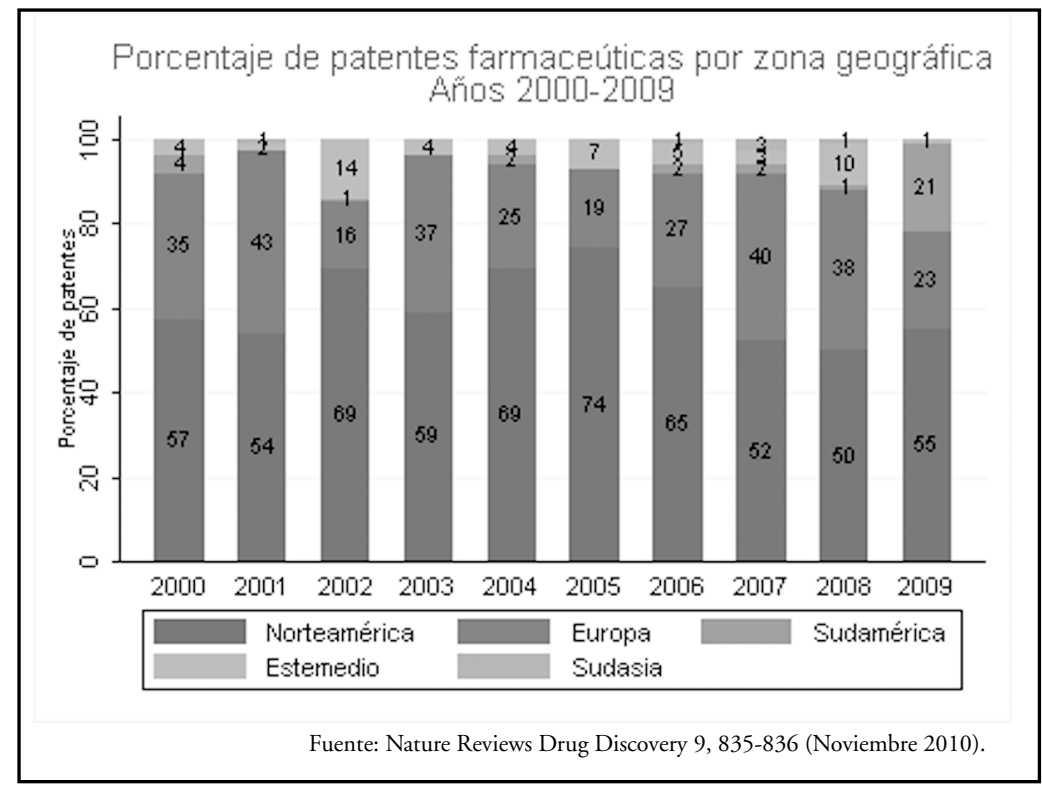

Figura 4. Panorama global sobre patentes farmacéuticas 


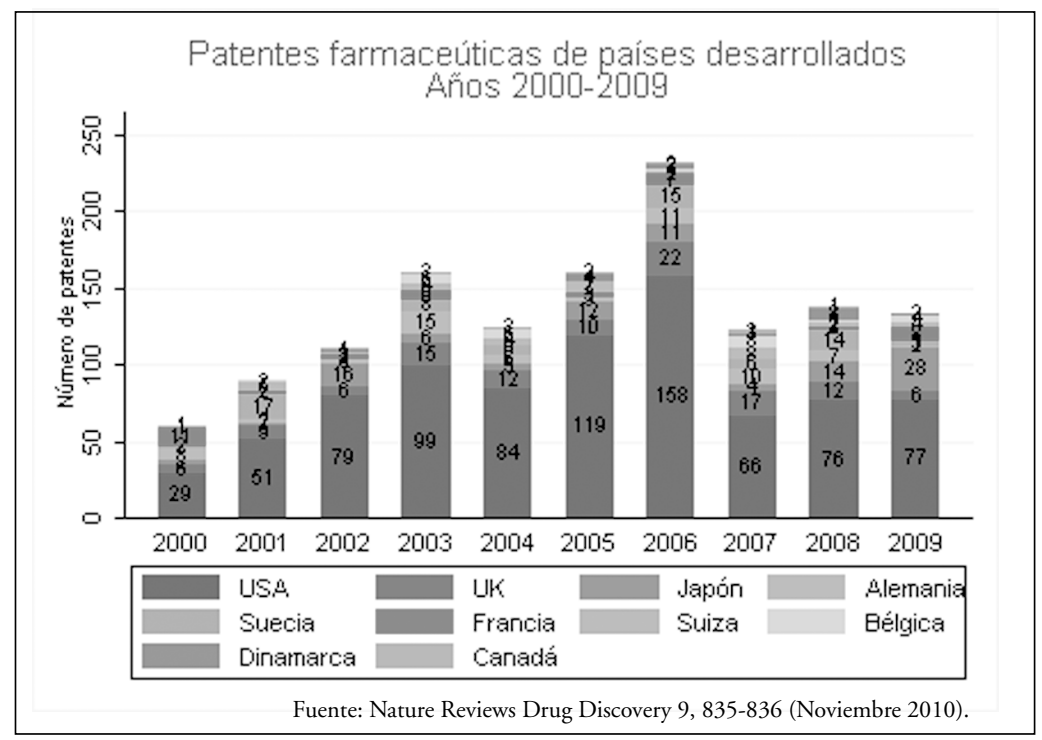

Figura 5. Panorama sobre patentes farmacéuticas de países desarrollados.

\section{EL LINKAGE Y LA COMPETENCIA POLIMÓRFICA: UN EJEMPLO DE PÉRDIDA DE BIENESTAR}

\section{El linkage}

Una de las instituciones más debatidas dentro del contexto de la PI farmacéutica y los TLCs, es el denominado Linkage que hemos definido como "[...] distintas formas o modelos de vincular, dentro del proceso de registro sanitario de un producto farmacéutico genérico, el análisis propiamente sanitario con el de eventuales infracciones a patentes que protegen al producto farmacéutico innovador o de referencia" ${ }^{17}$.

Una de las formas en que el Linkage se expresa, es como una medida precautoria, como por ejemplo la contenida el proyecto de ley de Linkage ("Proyecto Linkage"), supuestamente motivado en el cumplimiento del TLC suscrito entre Gobierno de la República de Chile y el Gobierno de los Estados Unidos de América ${ }^{17}$.

\section{Algunas notas sobre las medidas precautorias}

Las medidas precautorias se encuentran reguladas en Chile fundamentalmente en los artículo 290 a 302 del Código de Procedimiento Civil, y se basan, por su naturaleza, en dos principios que se explicarán a continuación: Periculum in mora y fumus boni iuris.

Periculum in mora es el peligro en la demora de la sentencia definitiva que se dictará en el proceso, o como dicen García de Enterría y Fernández, "la urgencia para evitar que la demora en la resolución del pleito principal cause perjuicios apreciables" ${ }^{20}$. $\mathrm{Al}$ respecto, Chiovenda afirma que se trata del "temor de un daño jurídico, es decir, la inminencia de un posible daño a un derecho o a un posible derecho"21. En nuestro derecho, el principio de periculum in mora, se contempla en la frase "asegurar el resultado de la acción” del artículo 290 del Código de Procedimiento Civil.

Por su parte, fumus boni iuris (humo de buen derecho) "se trata de un recaudo vinculado a la apariencia de buen derecho (lo que supone una menor rigurosidad en la prueba de la titularidad del derecho que recién se esclarecerá en la sentencia) que debe ser entendida como la probabilidad de que el derecho exista y no como su incontestable realidad, que solo se logrará al final del proceso"22. En Chile, en conformidad al fumus boni iuris, las medidas precautorias se decretarán por el juez competente, en la medida que se acompañen, por parte del solicitante, "[...] comprobantes que constituyan a lo menos presunción grave del derecho que se reclama" (artículo 298 del Código de Procedimiento Civil). 
Nuestros Tribunales de Justicia han sostenido al respecto, que "[ $[$ l l requisito en cuestión y que el legislador procesal estima necesario que debe acreditarse a través del proceso cautelar, es naturalmente la expresión del principio que lo guió en la reglamentación del instituto precautorio, esto es, la conciliación de la seguridad del derecho del actor y el respeto a la propiedad del demandado. En efecto, teniendo presente que por medio de las providencias cautelares se puede privar al sujeto pasivo de la administración, goce e incluso de la disposición de bienes de su propiedad, el legislador, movido por un criterio de estricta justicia y a fin de resguardar y respetar el derecho de propiedad del demandado, exige de aquel que deduce la acción cautelar acompane los referidos comprobantes que constituyan presunción grave del derecho que se reclama en la litis." 23 .

En definitiva, frente a una solicitud de medida precautoria, el juez es llamado a realizar un "análisis de mérito" de ésta, es decir, determinar si los comprobantes constituyen o no "a lo menos presunción grave del derecho que se reclama". En otras palabras, si de los medios de prueba aportados y que se le exhiben, se puede colegir un fumus boni iuris o "humo de buen derecho", lo que implica que, a criterio del juez, exista "verosimilitud"22 de lo pedido, de manera de poder conciliar o balancear la seguridad del derecho del actor y el respeto a la propiedad del demandado.

De todo lo anterior, se puede inferir que las medidas precautorias son por su esencia excepcionales, es decir, con un estándar de prueba alto ("presunción grave" y "riesgo inminente"), todo lo cual deberá probar quien lo alega, de acuerdo a las normas generales.

Pues bien, dentro de este contexto, si el titular de una patente farmacéutica que protegiese a un producto innovador, estimase que un producto genérico cuyo registro sanitario se está solicitando, infringe dicha patente, debiese solicitar una medida precautoria, a fin de impedir la comercialización de dicho producto genérico. Para lograr que sea concedida, deberá demostrar que existe periculum in mora (básicamente, perjuicio por pérdida de ventas del producto innovador) y fumus boni iuris (una presunción grave que el producto genérico infringe la patente).

\section{El proyecto linkage y las medidas precautorias sin análisis de mérito}

Contrariamente a lo señalado precedentemente, el Proyecto Linkage, en los incisos $2^{\circ}$ y $3^{\circ}$ del nuevo artículo 112 B contenido, establece una medida precautoria, pero sin análisis de mérito, es decir, sin que se tenga que acreditar periculum in mora y fumus boni iuris, sino que opera por medio de un esquema de presunciones respecto de los principales principios relacionados con las medidas precautorias en general, invirtiendo, en definitiva, la carga de la prueba.

Mediante esta medida precautoria sin análisis de mérito, el juez competente puede decretar "la suspensión del otorgamiento del registro sanitario de un producto farmacéutico [genérico] por el plazo de hasta un año" (inciso $1^{\circ}$ del artículo $112 \mathrm{~B}$ del Proyecto Linkage), sin que se tenga demostrar que existe periculum in mora (básicamente, perjuicio por pérdida de ventas del producto innovador) y fumus boni iuris (una presunción grave que el producto genérico infringe la patente).

Bastará que se acredite que el registro sanitario solicitado por una empresa genérica se refiere al mismo principio activo que el protegido por la patente, para que se presuma legalmente acreditada la existencia del derecho y la existencia de un riesgo de inminente infracción, y se conceda la referida medida precautoria.

\section{¿Cómo las medidas precautorias sin análisis de mérito, afectan a la competencia polimórfica?}

Una de las estrategias que la industria genérica ha utilizado para ingresar al mercado, sin infringir patentes farmacéuticas, es mediante la utilización de polimorfos distintos de la misma molécula de producto innovador ("competencia polimórfica").

Para explicar cómo una medida precautoria sin análisis de mérito puede afectar a la competencia polimórfica, (i) explicaremos el concepto de polimorfismos; (ii) entregaremos información sobre el mercado chileno de la atorvastatina cálcica trihidrato, como un caso concreto de competencia polimórfica exitosa; (iii) explicaremos cómo casos potencialmente exitosos de competencia polimórfica, pueden verse afectados por medidas precautorias sin análisis de mérito. 


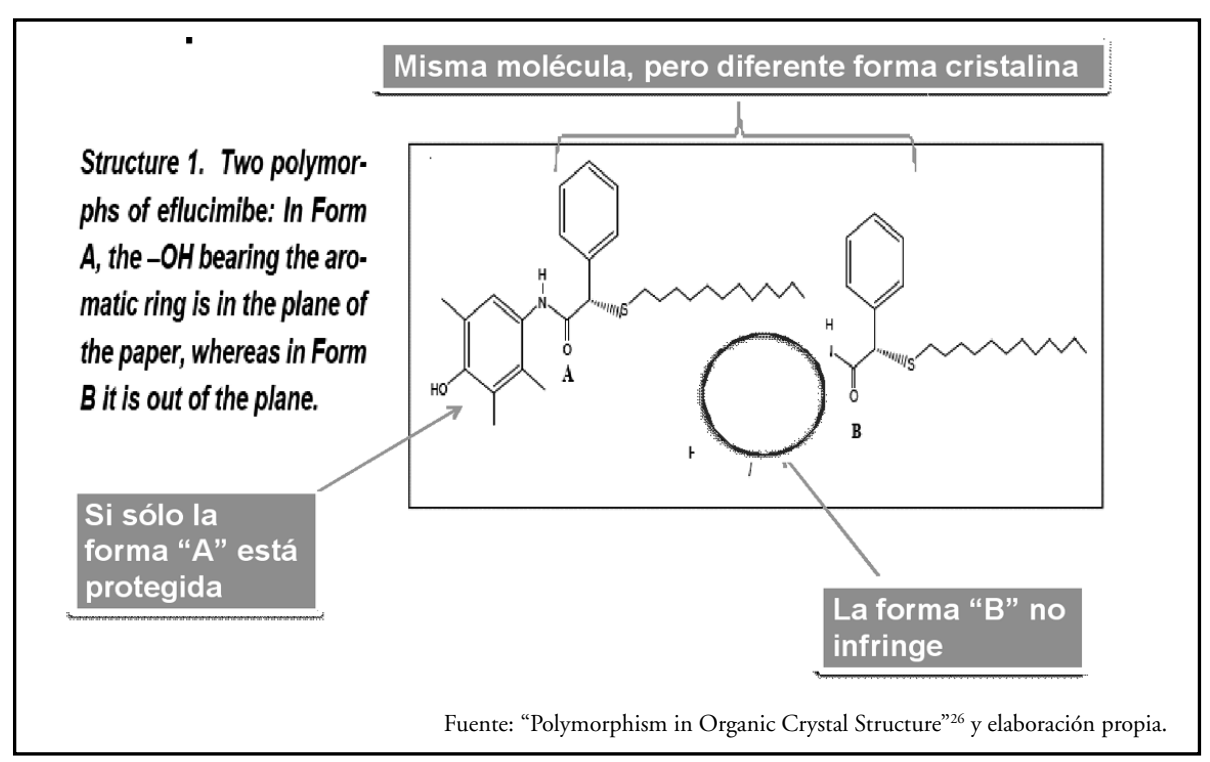

Figura 6. Representación del polimorfismo.

\section{El polimorfismo}

Este ha sido definido como "la capacidad de los principios activos para adoptar diferentes configuraciones espaciales" (24). La Figura 6, entrega un ejemplo de lo anterior, donde se aprecian dos polimorfos de la misma molécula (eflucimibe), pero con distinta configuración espacial: formas cristalinas A y B.

Esto tiene consecuencias tanto para la industria de innovación, como para la genérica: A la primera, le permite patentar sucesivas formas cristalinas de la misma molécula, ampliando el plazo de protección ${ }^{25}$; y, a la segunda, utilizar polimorfos no patentados, que no infringen las patentes del producto innovador.

Cada polimorfo tiene un patrón de difracción único, determinable habitualmente mediante la difracción de rayos $X$ (como se aprecia en la Figura 7) ${ }^{27}$, y que es una de las pruebas fundamental en los juicios por infracción de patentes.

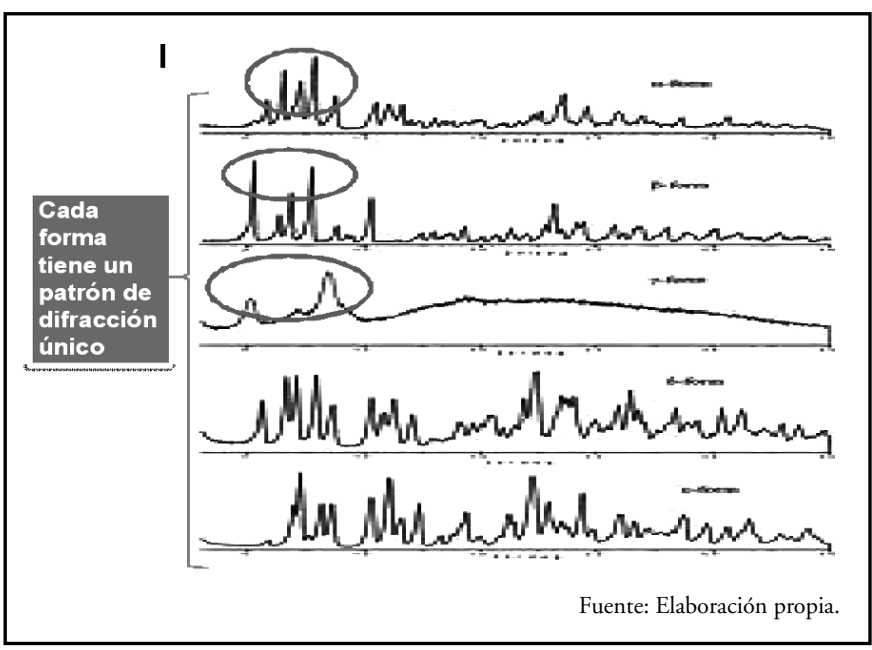

Figura 7. Representación de la difracción de rayos X. 


\section{Un caso exitoso de competencia polimórfica en Chile: La atorvastatina cálcica trihidrato}

Lipitor $^{\circledR}$ es el producto innovador cuyo principio activo es la atorvastatina cálcica trihidrato ("atorvastatina"), producto ampliamente utilizado a nivel mundial.

En Chile, no se solicitaron patentes que reivindican la atorvastatina en forma genérica (US 4.681.893) ni forma específica (US 5.273.995), así como tampoco procedimientos de preparación (US 5.003.080, US 5.216.174, US 5.298.627 y US 5.489.691). Sí se solicitaron y concedieron patentes que reivindican las formas cristalinas I, II, III y IV de atorvastatina (CL 39.690 de 31 agosto 1998; CL 41.138 de 31 agosto 2001; y 39.996 de 14 junio 1999).

A fin de no infringir dichas patentes, la industria genérica utilizó la atorvastatina amorfa, con lo cual se pudo contar con una alternativa genérica, desde el año 1997 (Figuras 8 y 9).

Como se aprecia, las unidades de atorvastatina amorfa genérica, son las que mayoritariamente abasteció la demanda existente (Figura 8). Por su parte, mientras los precios promedios de Lipitor ${ }^{\circledR}$ a fines de 2011 se ubican en torno a los USD 55, el de las alternativas genéricas amorfas, para igual período, en torno a los USD 5.

Ello ha generado importantísimos ahorros, en un medicamento que fundamentalmente se adquiere mediante gasto de bolsillo.

\section{La afectación de la competencia polimórfica mediante la medidas precautorias sin análisis de mérito}

En un caso teórico, si la molécula innovadora $Y$ sólo estuviese protegida mediante una patente

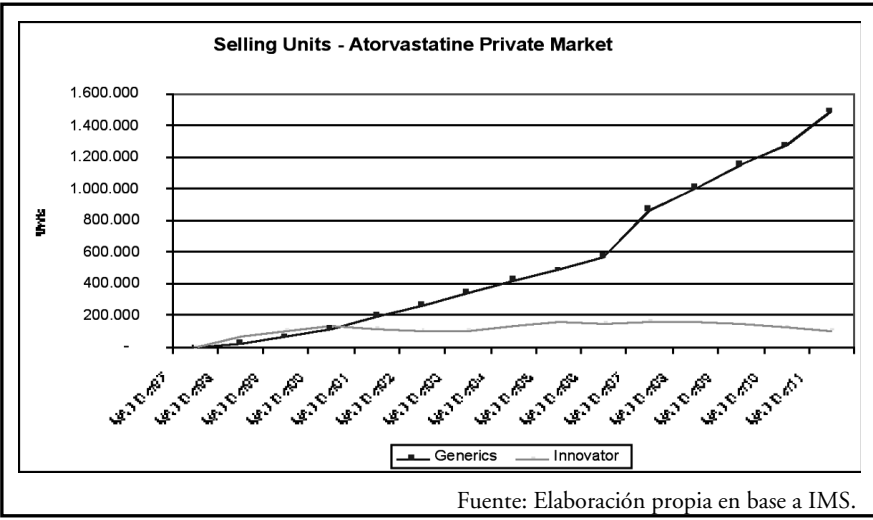

Figura 8. Unidades en mercado privado (farmacias).

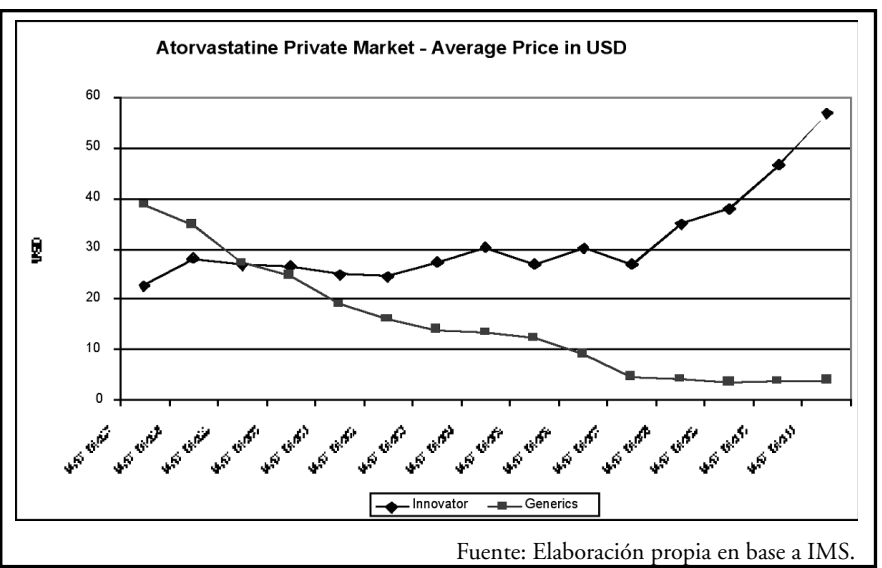

Figura 9. Valores en mercado privado (farmacias). 


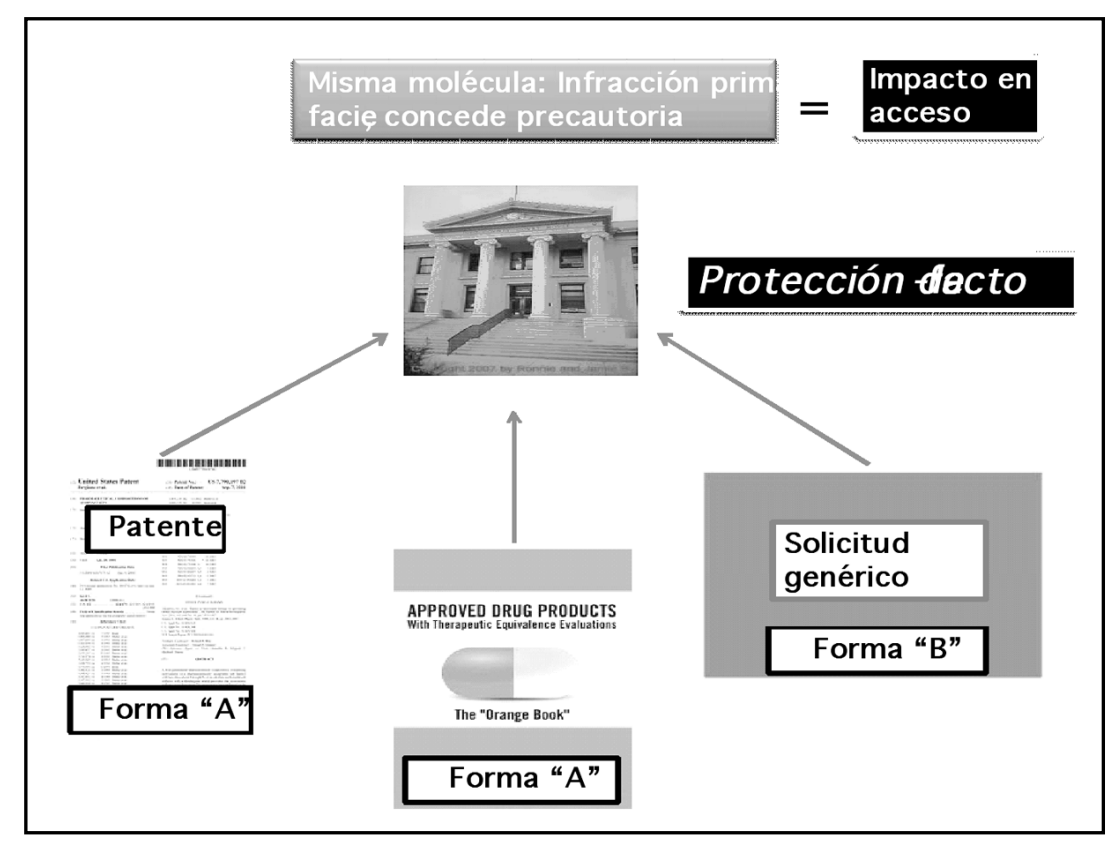

Figura 10. Representación del funcionamiento de una medida precautoria sin análisis de mérito.

que reivindica la forma cristalina $\mathrm{A}$, la industria genérica podría comercializar la forma B de dicha molécula, sin infringir la patente.

Ahora, para poder determinar con certeza cuál forma cristalina o polimorfo está utilizando la industria genérica, es necesario analizar el patrón de difracción de la molécula utilizada, mediante, por ejemplo, la difracción de rayos X. Sin dicho test, sólo podrá saberse que la industria genérica está comercializando la molécula $Y$, al igual que la empresa innovadora.

En caso de que exista en el ordenamiento jurídico, un linkage como medida precautoria sin análisis de mérito, la empresa innovadora no estará obligada a demostrar que existe periculum in mora (básicamente, perjuicio por pérdida de ventas del producto innovador) y fumus boni iuris (una presunción grave que el producto genérico infringe la patente). En buenas cuentas, no deberá aportar un informe técnico o pericial (apoyado, por ejemplo, en un test de difracción de rayos X), que persuada al juez de que existe una presunción grave que la patente está siendo infringida por la industria genérica.

Bastará que le demuestren, a grandes rasgos, que la existencia de la patente protege a la molécu- la $Y$, la que también pretende o está siendo comercializada por la industria genérica. Es decir, el juez no podrá, ni tendrá que cerciorarse que se tratan de formas cristalinas distintas (A y B) de la misma molécula $Y$.

Como se muestra en la Figura 10, ante esta “ceguera del juez" (sólo ve que tanto lo patentado, como lo comercializado por la industria genérica es la molécula $Y$, sin distinguir entre las distintas formas cristalinas), bastará acreditar que el registro sanitario solicitado por una empresa genérica se refiere a la molécula $Y$, que es el mismo protegido por la patente, para que se presuma legalmente acreditada la existencia del derecho y la existencia de un riesgo de inminente infracción, con lo que el juez deberá conceder la medida precautoria, suspendiendo el otorgamiento del registro sanitario.

Lo anterior, produce una extensión o protección de-facto, que permite que la patente impida la comercialización de medicamentos genéricos que no la infringen.

Ello impedirá que se genere competencia para el innovador, y que bajen los precios, aumentando el acceso al medicamento en cuestión. 


\section{CONCLUSIONES}

Un modelo de PI farmacéutica debiese poder balancear los incentivos para I\&D, garantizando, además, el adecuado acceso a los medicamentos, de manera de optimizar el bienestar general. El sistema de PI farmacéutica elegido debiese considerar la realidad (generador o no de I\&D farmacéutico) del país donde se va a implementar.

Los países en vías de desarrollo, sólo eligen dentro de márgenes estrechos los modelos de PI farmacéutica que implementarán, dado que estos son impuestos, en gran medida por los países desarrollados generadores de I\&D farmacéutico como parte del trade-off por acceso a mercados desarrollados, en la negociación de los TLCs.

El Linkage como medida precautoria sin análisis de mérito, es una de las instituciones habitualmente impuestas mediante los TLCs. Esta genera una protección de-facto, más allá de los efectivamente reivindicados en la patente, por lo que es capaz de bloquear la entrada de genéricos al mercado, a pesar que estos no infrinjan.

Ello, limita la competencia, la baja de precios y el acceso a medicamentos, generando pérdidas de bienestar.

\section{Agradecimientos}

Mis sinceros agradecimientos por toda la colaboración y ayuda en la preparación de este paper a mi ayudante Valentina Santibáñez, de la Facultad de Derecho de la Universidad de Chile.

\section{REFERENCIAS BIBLIOGRÁFICAS}

1. Cameron G. Innovation and economic growth. Discussion Paper No. 277. London: Centre for Economic Performance; London School of Economics and Political Science; 1996.

2. Rosenberg N. Innovation and economic growth [en línea]. OECD; 2004 [consultado en septiembre de 2012]. Disponible en: http:// www.oecd.org/dataoecd/55/49/34267902.pdf.

3. Atun R, Harvey I, Wild J. Innovation, patents and economic growth. Int J Innov Mgt 2007; 11: 279.

4. Fogel R. Economic growth, population theory, and physiology: the bearing of long-term processes on the making of economic Policy. Am Econ Rev 1994; 84(3): 369-395.
5. Fogel R. The relevance of Malthus for the study of mortality today: long-run Influences on health, mortality, labor force participation, and population growth. NBER Historical Working Paper 1994; (54): 231-284.

6. Fogel R. Nutrition, physiological capital, and economic growth. Paper presented at the Senior Policy Seminar on Health, human Capital and Economic Growth: Theory, Evidence and Policies. Pan American Health Organization and InterAmerican Development Bank. 2002, 3-4 octubre; Washington D.C.

7. Liu G, Dow W, Fu A, Akin J. Income growth in China: on the role of health. Paper presented at the 4th World Congress of the International Health Economics Association (IHEA); 2003, San Francisco.

8. World Bank. Poverty and human development: world development report. Washington, D.C.: World Bank; 1980.

9. Barro R. Health and economic growth. Paper presented at the Senior Policy Seminar on Health, human Capital and Economic Growth: Theory, Evidence and Policies. 2002; 3-4 octubre; Washington D.C.

10. Dimasi J, Hansen R, Grabowski H. Reply: Extraordinary claims require extraordinary evidence. J Health Econ 2005; 24(5): 1034-1044.

11. Adams $\mathrm{C}$, Brantner V. Estimating the cost of new drug development: is it really $\$ 802$ million? Health Affairs 2006; 25(2): 420-428.

12. Light $\mathrm{D}$, Warburton R. Demythologizing the high costs of pharmaceutical research. BioSocieties 2011; 6: 34-50.

13. European Commission. DG Competition Staff Working Paper. Pharmaceutical sector inquiry. [en línea]. 2008 [consultado en septiembre de 2012] Disponible en: http://ec.europa.eu/competition/sectors/ pharmaceuticals/inquiry/preliminary_report.pdf.

14. Cárdenas J. Toward a more balanced pharmaceutical patent system for developing countries: some preliminary thoughts. J Generic Med 2011; 8(2): 104-110.

15. Kumar N. Intellectual property rights, technology and economic development: experiences of Asian countries. Econ Political Weekly. 2003; 38(3).

16. Palombi L. Gene Cartels: biotech patents in the age of free trade. Cheltenham, UK: Edward Elgar Publishing; 2009. 
17. Cárdenas J. El uso de la información no divulgada y el linkage en el TLC con EE.UU: ¡a qué realmente se obligó al Estado de Chile y cómo se ha cumplido? Rev Derecho Económico Internacional 2011; 1(2).

18. Dahos P. Expanding Intellectual Property's Empire: the Role of FTAs. Regulatory Institutions Network, Research School of Social Sciences, Australian National University. 2003 [en línea] $<$ http://ictsd.net/downloads/2008/08/drahos-fta2003-en.pdf> [consulta: septiembre de 2012].

19. Roffe P. Bilateral agreements and a TRIPS-Plus world: the Chile - USA Free Trade Agreement. TRIPS Issues Paper No. 4. Otawa: Quaker International Affairs Programme; 2004.

20. García de Enterría E, Fernández T. Curso de derecho administrativo. $T^{\circ}$ II. Madrid: Civitas; 1998.628 p. 21. Chiovenda G. Instituciones de derecho procesal civil.
Buenos Aires: Valletta Ediciones; 2005. 299 p.

22. Cassagne J, Perrino P. El nuevo proceso contencioso administrativo de la Provincia de Buenos Aires. Buenos Aires: Lexis Nexis; 2006. 341 p.

23. Corte de Apelaciones de Santiago, Rol N ${ }^{\circ} 2111$ 1989, considerando $1^{\circ}$.

24. Martín A, Molina E. Polimorfismo farmacéutico. OFFARM. 2006; 25(8): 94-100.

25 . Veru P. Polymorph patents; how strong they are really?. Int J Intellect Prop Manag 2011; 4(4): 297-306.

26. Bharat D, Mahesh M, Jigarkumar P, Bhaveshkumar D. Polymorphism in organic crystal structure. Res J Chem Environ 2012; 16(3).

27. Papathoma S. Patenting polymorphs at the European Patent Office [en línea]. 2006 [consultado en septiembre 2012]. Disponible en: <http://www.pcb.ub.edu/centredepatents/pdf/ cursos/dillunsCP/papathoma_polymorphs.pdf. 